\title{
Mycoviruses: future therapeutic agents of invasive fungal infections in humans?
}

\author{
W. W. J. van de Sande • J. R. Lo-Ten-Foe • \\ A. van Belkum • M. G. Netea • B. J. Kullberg • \\ A. G. Vonk
}

Received: 28 March 2010 /Accepted: 12 April 2010 /Published online: 2 May 2010

(C) Springer-Verlag 2010

\begin{abstract}
Invasive fungal infections are relatively common opportunistic infections in immunocompromised patients and are still associated with a high mortality rate. Furthermore, these infections are often complicated by resistance or refractoriness to current antimicrobial agents. Therefore, an urgent need exists for new therapeutic strategies based on the identification of new microbial targets and novel antimicrobial agents. One such hypothetical therapeutic strategy may involve the use of mycoviruses that are able to selectively infect fungi. Current knowledge of mycoviruses of human pathogenic fungi and the scope for using (recombinant) mycoviruses as future biological control agents are reviewed here.
\end{abstract}

\section{Introduction}

Fungal infections such as invasive candidiasis and aspergillosis cause a high morbidity and mortality in immunocompromised patients. Although timely administration of

W. W. J. van de Sande · A. van Belkum· A. G. Vonk $(\bowtie)$

Department of Medical Microbiology and Infectious Diseases, Erasmus MC, University Medical Center Rotterdam,

s-Gravendijkwal 230,

3015 CE Rotterdam, The Netherlands

e-mail: a.vonk@erasmusmc.nl

\section{J. R. Lo-Ten-Foe}

Department of Medical Microbiology,

University Medical Center Groningen, University of Groningen,

Groningen, The Netherlands

M. G. Netea • B. J. Kullberg

Department of Medicine, Radboud University Nijmegen Medical

Center, and Nijmegen Institute for Infection, Inflammation and Immunity (N4i),

Nijmegen, The Netherlands antifungal therapy has a significantly positive influence on the outcome of infection in such patients, treatment failure remains a major problem $[1,2]$. As well as pivotal development of adjunctive immunotherapy to enforce antifungal host immune response, new therapeutic strategies are needed to selectively combat aspergillosis and other invasive opportunistic fungal diseases.

Mycoviruses are viruses that selectively infect fungi. Although the first reports on mycoviruses date from the 1960s [3], our knowledge and understanding of mycoviruses is still in its infancy. Moreover, current mycovirus publications primarily concern economically important fungi such as cultivated mushrooms, yeasts, and fungal pathogens of plants. To our knowledge, the use of mycoviruses as a tool to combat invasive fungal infection in animals and humans has not yet been suggested, let alone explored in any detail.

\section{Mycovirus biology and interaction with the fungal host}

The genetic information of mycoviruses is either encoded by double-stranded RNA (dsRNA), single-stranded RNA with or without a reverse transcription step for replication (ss(+)RNA-RT), or double-stranded DNA (dsDNA) [4]. The 8th report on virus taxonomy of the International Committee for Taxonomy of Viruses (ICTV) lists more than 90 mycoviruses covering 10 viral families [5]. A complete list of mycoviruses of plant pathogenic fungi can be found in a recent review by Pearson et al. [4]. Despite the limited data on mycoviruses of human pathogenic fungi, evidence is provided that mycoviruses do exist in various fungal genera that are pathogenic to humans [618]. The mycoviruses that are associated with fungal genera that can cause human fungal disease and are also formally known by the ICTV are listed in Table 1. In addition, viral 


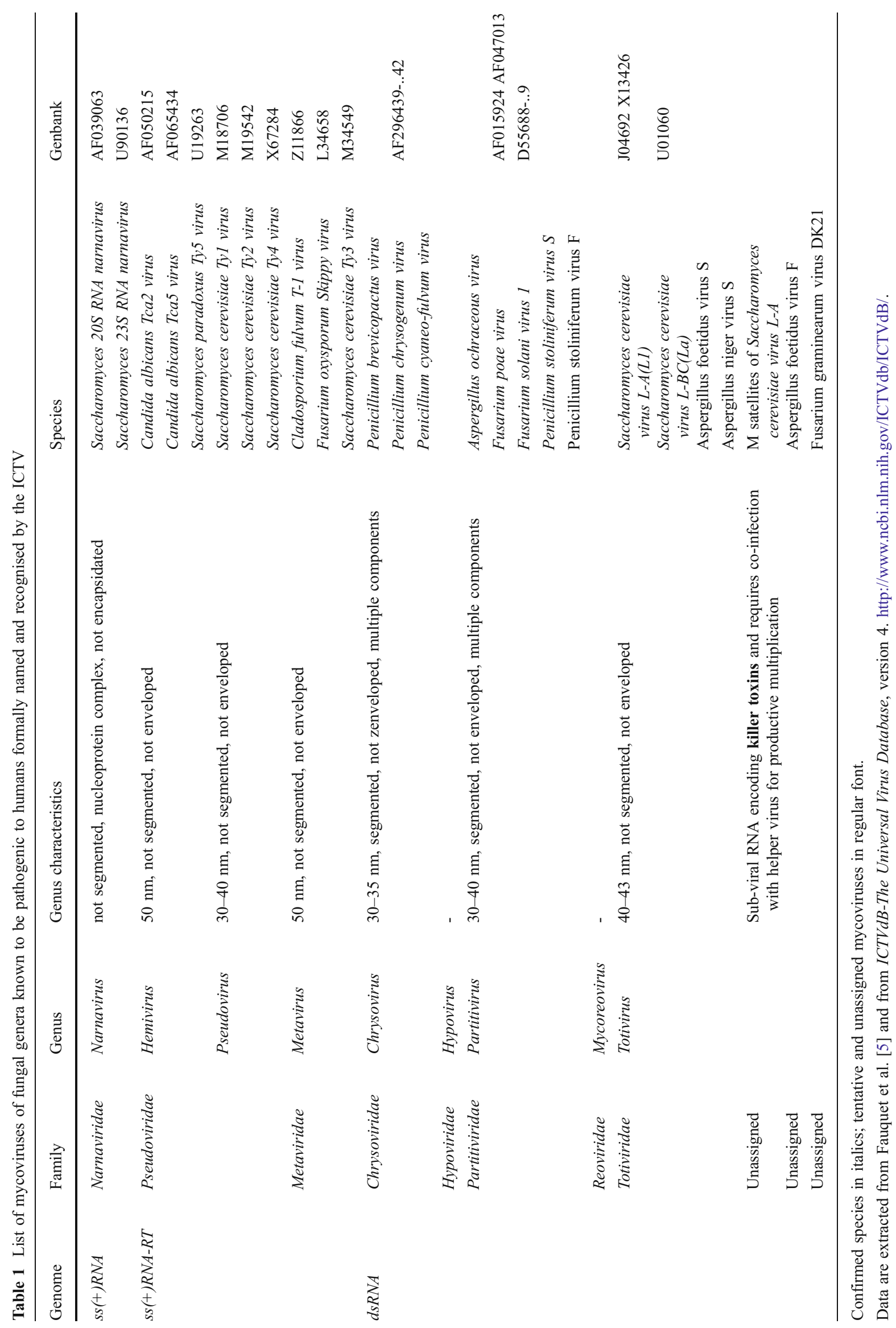


particles have also been detected in Alternaria alternata, Rhizopus and Mucor spp., Candida albicans, C. tropicalis, $C$. lipolytica and $C$. curvata, but these fungal genera are omitted from Table 1 because they are not listed in the ICTV report [11-14, 16, 18].

To date, the majority of characterised mycoviruses of pathogenic fungi have dsRNA genomes. These viruses have subsequently been grouped into five families: Partitiviridae, Totiviridae, Chrysoviridae, Reoviridae, and Hypoviridae [5]. The families mainly differ in the number of genome segments and the way they are packaged. An almost universal trait of the dsRNA mycoviruses is the presence of capsids (except for Hypoviridae), which are selectively porous protein compartments in which the genome and replicase are contained. Nucleotides diffuse into this compartment and nascent positive sense strands are extruded from it. DsRNA mycoviruses are not surrounded by an envelope. A synopsis of the dsRNA viruses and their characteristics relevant to human pathogenic fungi is provided in Fig. 1.

\section{Transmission of mycoviruses}

\section{Intracellular transmission}

Mycoviruses are mainly spread by vertical transmission through asexual or sexual spore formation, with asexual sporulation being the most efficient means of transmission. Transmission also occurs horizontally via cytoplasmic exchange during cell division and mating with strains that, depending on the genus, do not have to be genetically compatible for virus transfer to occur [9, 19-22]. As a rule, however, when two fusing hyphae are not compatible, they recognize each other as nonself, which triggers programmed cell death (PCD). In aspergilli, the genes involved in activation of $\mathrm{PCD}$ reactions are currently being characterised and regarded as a promising approach to combat invasive aspergillosis [23-26]. Genetic incompatibility is mostly followed by death of the hyphal fusion cell, the so-called heterokaryon, and often of surrounding cells. When this occurs, transmission of mycoviruses fails (Fig. 2). Rejection of heterokaryon formation has been observed to be relatively mild or absent when hyphae of less related Aspergillus species fuse [9].

Direct transmission of mycoviruses from one fungal species to another occurred following another experimental means, namely, induced fusion of cell wall-free fungi, socalled protoplasts. Using protoplast fusion, mycoviruses may even be transferred between two fungal compartments of strains that are heterokaryon incompatible [9].

\section{Extracellular transmission}

Bearing in mind that crossing the cellular membrane is a key step in the infectious life cycle of all viruses, it is understandable that the rigid cell wall in fungi serves as a membrane shielding structure constituting a barrier to extracellular virus uptake. For instance, dsRNA mycoviruses with an average size of $40 \mathrm{~nm}$ are approximately nine times the pore-size of the cell wall matrix in Candida species [27]. The cell wall thus prevents the virus from reaching the cell membrane to gain entry. Consequently, mycoviruses are unable to initiate fungal infections by extracellular routes. However, whereas the understanding of (enveloped) virus entry via membrane fusion is well advanced for mammalian viruses or viruses that selectively

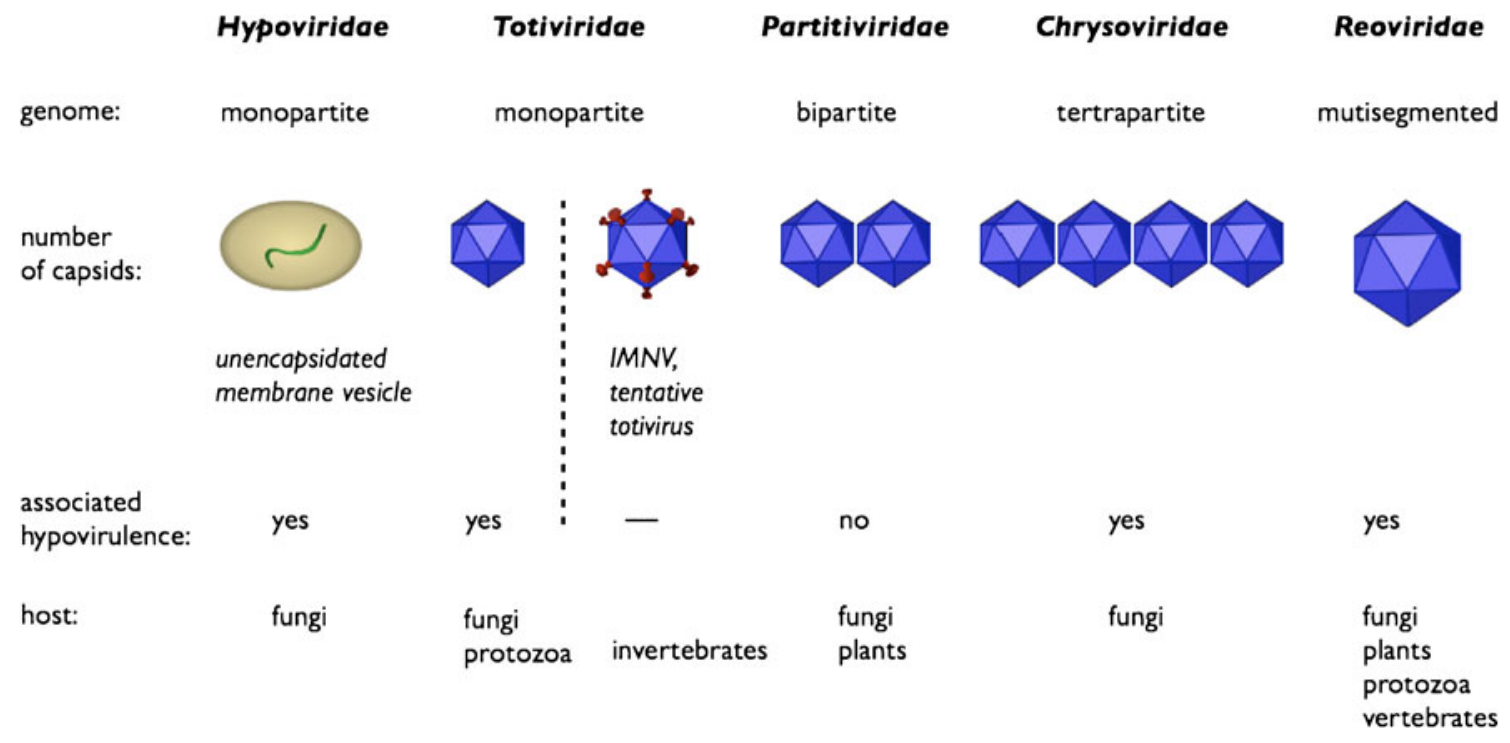

Fig. 1 List of the predominating genome type of the dsRNA mycoviruses. Taxonomic families that are associated with pathogenic fungi are shown with the genome composition, virus structure, associated hypovirulence, as well as the host range of the respective viral families 
Fig. 2 Transfer of mycoviruses between fungal hyphae is dependent on the compatibility of the donor and acceptor hyphae upon contact

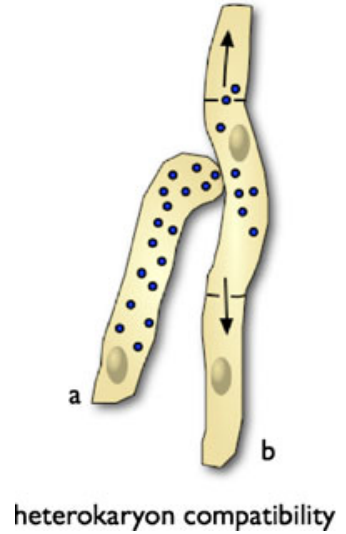

nucleus

- mycovirus

viral spread infect bacteria (bacteriophages), the entry mechanisms for non-enveloped viruses, virus-like particles or naked virus-like dsRNA are still in infancy. Therefore, it may well be that the overall routes and mechanisms of extracellular virus transfer still remain to be elucidated. Infection by the extracellular route could thus far only be achieved in special experimental settings using protoplasts. Applying this method, purified viral particles belonging to the dsRNA families of Partitiviridae, Totiviridae, and Reoviridae successfully infected fungal protoplasts [10, 28, 29].

\section{Experimental introduction of genetic information}

Fungi have been transfected using an infectious complementary DNA (cDNA) copy of mycovirus RNA [30]. Transfected fungi showed cytoplasmically replicating dsRNA, demonstrating that a synthetic transcript corresponding to the coding strand of mycovirus dsRNA can initiate an infection when introduced into fungal protoplasts [30]. Again, this has putative therapeutic implications.

Mycelial spread of mycoviruses after transmission

In septate fungi, hyphal compartments are interconnected through hyphal pores. Replicating mycoviruses are thus able to spread throughout the colony via plasma streaming $[28,30]$ (Fig. 2). If the spread of mycoviruses throughout the colony occurs mainly via plasma streaming and not via fusion with neighbouring hyphae, the viral replication rate may be the limiting factor of transmission. Even after successful mycovirus transmission, persistence may not be obtained. This may be the case when compatible hyphae that form a heterokaryon are both infected with a different mycovirus. Co-infections may be generated, but the mycovirus in the acceptor fungus may also be replaced by the mycovirus from the donor. Indeed, viruses are not always detected in the colonies derived from the protoplast/ hyphae fusion products [9]. This suggests that mycoviruses can be selectively eliminated upon regeneration and outgrowth of (transfected) protoplasts as a result of intrahost competition between viruses.

\section{Symptoms associated with mycovirus infection}

Generally, mycoviruses cause latent and persistent infections [31]. Some mycovirus families are connected with variable phenotypic effects such as hypovirulence or killer phenomena in their host. Hypovirulence is, among other characteristics, defined as reduced pigmentation, reduced asexual sporulation, loss of fertility, or reduced growth rate. Hypovirulence-associated mycoviruses have ssRNA or, mainly, dsRNA genomes (Fig. 1) [8, 32-35]. The killer phenomena are induced by proteins encoded by satellite dsRNA that are associated with Totiviruses (discussed below) [36].

Isolation of mycoviruses and maintenance

Once fungi are successfully transfected, the observed infection patterns are very stable when subcultured [9, 28]. Furthermore, viruses present in Aspergillus isolates are highly efficiently transmitted to asexual progeny [21].

Limited data exist regarding the amount of mycoviruses that can be isolated from infected fungi and their stability after isolation. Most viruses have only been isolated with a relatively low yield. Hillman et al. showed that 3-6 $\mu \mathrm{g}$ of purified reovirus was obtained from each purification reaction, representing 21 of infected fungi. These isolated Reoviridae were quite stable and retained infectivity upon prolonged storage [29]. In contrast, Saccharomyces cerevisiae Totivirus preparations stored refrigerated for three weeks became non-infectious [10]. Thus, isolation, production, purity and stability of mycoviruses of interest remain to be assessed. 


\section{Mycoviruses and toxins}

As stated above, some mycovirus infections have a toxinmediated killing capacity. Although a filamentous basidiomycete fungus, Ustilago maydis, is known to secrete killer toxins encoded by cytoplasmic dsRNA mycoviruses that are lethal to mycovirus-free susceptible strains of the same fungus [37-39], most killer phenotypes and their applications characterized to date are derived from yeasts. Killer yeasts are immune to their own secreted toxins, while remaining susceptible to others. Toxin-coding cytoplasmic dsRNA-mycoviruses have been detected in Saccharomyces cerevisiae and in non-conventional yeasts such as Hanseniaspora uvarum and Zygosaccharomyces bailii [10, 40]. In contrast to the $S$. cerevisiae toxins, killer toxins of nonSaccharomyces yeasts and especially those secreted by virus-infected killer strains of the yeasts $H$. uvarum and $Z$. bailii show a broad-spectrum antimycotic potential to human pathogenic strains, such as Candida albicans, Sporothrix schenkii, and Fusarium sp. [36, 41]. The toxin isolated from $Z$. bailii, zygocin, effectively kills $C$. albicans, C. glabrata and C. tropicalis yeast cells and germlings. Moreover, on a molar basis, zygocin is even more effective in killing yeasts than antifungal agents such as clotrimazole or miconazole, suggesting that zygocin is a promising antifungal agent [42].

The outer cell wall layer of yeasts predominantly consist of mannoproteins, connected to a glucan skeleton consisting of linear and branched beta-1,3- and beta-1,6-D-glucans, and to a much lesser extent of chitin which mainly concentrates in bud scars [43]. In the search for novel and more selective antifungal agents, fungal cell wall components represent primary targets, as these structures are restricted to yeasts and higher fungi and do not occur in human cells $[44,45]$. Each of the mentioned cell wall components has been shown to act as the primary binding site for different yeast killer toxins [46-49]. In addition, for killer toxins secreted by various strains of the yeast Hansenula it was demonstrated that these toxins not only bind to yeast cell wall components, but that they also strongly inhibit de novo L-1,3-D-glucan biosynthesis [50, 51]. Given the cell wall related activity of mycovirus-encoded killer toxins, antifungal research has indeed focused on the possible use of yeast killer toxins as novel antifungal agents for the treatment of fungal infections [52]. Clinical recovery as well as negative mycological test cultures of experimental dermatomycosis in animals proved to be clearly associated with topical killer toxin treatment [53]. However, although some researchers have shown that topical applications in the treatment of superficial lesions might well be possible, one drawback of most yeast killer proteins is that they exhibit their cytotoxic activity only at temperatures between $20^{\circ} \mathrm{C}$ and $30^{\circ} \mathrm{C}$ within a narrow $\mathrm{pH}$ range $[53,54]$. Therefore, yeast toxins are unsuitable as direct applications for oral and/or intravenous administration [55]. Killer toxins, however, fuelled the development of new antifungal agents that mimick the antimicrobial activity of killer toxins, so-called killer antibodies and killer antibodyderived peptides. These derivatives have shown activity against various human fungal pathogenic fungi including $C$. albicans and may be therapeutic when administered parentally. For reviews of killer toxin/antibodies the reader is referred to Marquina et al. [49], Magliani et al. [55], and Schmitt and Breinig [40].

\section{Viruses as therapeutic agents for infections in humans}

The idea to cure infections in humans with viruses as biological control agents is not new. Most research has been conducted using viruses that specifically and uniquely search and destroy bacteria. These bacteriophages-'eaters of bacteria' - have been known since the early 20th century [56]. To offer support for the contention that a strategy using mycoviruses in the treatment of medically important fungi can be effective, analogous research using bacteriophages for treating bacterial infections is briefly reviewed.

Bacteriophages are ubiquitous and found in many different environments including soil, human and animal bodies; they do not attack human cells and exist as partners in microbiological eco-systems in mammals. Bacteriophages may be divided into a number of basic types based on morphological and genome analysis. The genome types are dsDNA, ssDNA, dsRNA and ssRNA. The most prevalent bacteriophages are tailed and all tailed bacteriophages have dsDNA. Furthermore, these tail fibres confer host specificity within this group [5].

Although a large number of publications have suggested that bacteriophages may be effective therapeutic agents in clinical settings, most published studies are uncontrolled or anecdotal and do not meet the criteria of modern evidence [56]. However, recently, proof of principle has been provided as bacteriophage therapies have been developed for multiresistant bacteria and other difficult to treat infections [57, 58]. For instance, it has been shown that a bacteriophage with lytic activity against vancomycin resistant Enterococcus faecium (VRE) successfully cured mice from VRE bacteraemia [59]. A review of various experimental infections treated with bacteriophages can be found in the work of O'Flaherty et al. [60]. In addition, the therapeutic bacteriophage of VRE bacteraemia was well tolerated in a phase I clinical trial [57]. Other clinical trials have shown that bacteriophages could be safely administered, even to children, and demonstrated cost effectiveness over antibiotic treatment of infections caused by multidrug-resistant bacteria [61, 62]. Furthermore, the first results of a randomised, double- 
blind, placebo-controlled phase I/II clinical trial of a bacteriophage therapeutic targeting long-term ear infections with $P$. aeruginosa refractory to antibiotic showed both efficacy and safety [63].

In tandem with the resurgent interest in bacteriophages as therapeutic agents and the advent of high throughput sequencing, the number of bacteriophage genomes sequenced to completion has drastically increased to $>500$ [60]. Although host species specificity is the rule for most bacteriophages investigated, many bacteriophages have developed efficient methods to change their host range via genetic mechanisms [64]. The dsDNA Escherichia coli bacteriophage, Phi K1-5, for example, has shown to be capable of infecting $E$. coli strains that possess either the $\mathrm{K} 1$ or the K5 polysaccharide capsule due to possession of two different tail fiber proteins. The arrangement of genes suggests that this bacteriophage can broaden its host range by horizontal gene transfer [65].

Although bacteriophages have a unique and limited bactericidal spectrum, they are almost as numerous as bacteria and the development of therapeutic bacteriophages is therefore hardly problematic. Furthermore, nowadays, engineering of genes involved in host recognition may be an additional approach for generating an expanded host range.

\section{Host range expansion using genetic engineering}

\section{Pyocins}

Engineering of genes involved in host recognition results in host range expansion. Evidence is mostly provided by the studies of R-type pyocins. Certain Pseudomonas aeruginosa strains produce R-type pyocins (henceforth called pyocins), protein particles resembling non-flexible and contractile tails of bacteriophages [66]. Although many pyocin genes share common ancestry with bacteriophage genes, pyocins differ from bacteriophages, for they do not contain nucleic acid and cannot replicate. Both bacteriophages and pyocins bind to an accessible receptor on the target bacterium, but pyocins kill the target bacterium by a different mechanism. Pyocins kill bacteria by first binding to a cell surface structure via tail fibers, followed by contraction of the sheath and insertion of their hollow core through the cell envelope resulting in depolarization of the cytoplasmic membrane and cell death [67]. Pyocin has been shown to increase survival and reduce bacterial counts in a lethal murine experimental Pseudomonas peritonitis model [68]. The bactericidal specificity of pyocins is conferred by their tail fibers encoded by prf15. A chaperone, encoded by prfl6 immediately downstream of prf15, is required for tail fiber assembly [69]. Chimeric tail fusion fibers that bind to presumably different bacterial surface molecules have been engineered. The generated chimeric tail fibers that formed active pyocins resulted from many trials of empirically chosen fusion sites between prf15 and portions of bacteriophage tail/spike fibers. The engineered fusions between $\mathrm{N}$-terminal portions of the pyocin tail fiber and various $\mathrm{C}$-terminal portions of the bacteriophage tail/spike fibers resulted in pyocin host range expansion from Pseudomonas to Yersinia and various E. coli strains [70, 71]. Scholl et al. further envisage that an unlimited amount of chimeric pyocins can be created based on the presence of a vast number and diversity of bacteriophage tail fibres combined with the application of phage display techniques. This may provide even greater diversity of binding specificities than exists naturally on pyocins and could lead to an almost unlimited number of bactericidal agents.

\section{Plant viruses}

Similarly, plant viruses have been genetically modified to express heterologous proteins for vaccine development. To this purpose, coat protein genes of several plant viruses have been genetically altered to express foreign antigenic epitopes of human or animal origin as fusions to the viral coat protein. These foreign epitopes are exposed and displayed on the surface of chimeric virus particles [72]. Although the size of the peptide fusions that still permit virus assembly is limited [73], several strategies have been developed to overcome assembly problems for long or difficult peptides. These include "Foot and Mouth Disease Virus 2A peptide coat protein (CP) fusion strategy" and the so-called "leaky stop codon CP fusion strategy", which would cause most of the $\mathrm{CP}$ produced to be unfused, while a small portion would be fused to the peptide displayed on the surface [74-76].

Fusion proteins have to be compatible with normal viral assembly and fitness, and steric hindrance or interference with virus movement must be avoided to sustain infection. Indeed, recombinant viruses expressing foreign antigenic peptides on their surface can remain infectious and retain the foreign sequences during passage from plant to plant $[73,76]$. Many stable mutants have already been prepared that allow specific modification of the capsid surface of plant viruses (for a review, see [77]).

\section{Mycoviruses}

Likewise, in mycovirus research for vaccine development against aspergillosis, the transposon Ty1 of yeast Saccharomyces cerevisiae has successfully been used for the expression of Aspergillus peptides on its surface. This bifunctional virus-like particle engineered to contain peptides representing dominant $\mathrm{T}$-and $\mathrm{B}$-cell epitopes of 
Aspergillus proved more potent in stimulating memory immune responses [78].

One possible scenario that can be derived from the results of genetic modification of bacteriophages, pyocins, plant viruses, and mycoviruses described above, is the generation of a selective mycovirus that is transmitted extracellular in an efficient way. Genetic modification of structures involved in mycovirus binding to the target fungus may be the first that comes to mind. To date, such a mycovirus is not known to exist. Recently however, the infectious myonecrosis virus (IMNV) was discovered as the cause of infectious myonecrosis in penaeid shrimp. IMNV is tentatively considered as a totivirus due to its RNAdependent RNA-polymerase (RdRp) that matches significantly with the consensus sequence of the RdRp of the Totiviridae family [79]. As outlined above, totiviruses are able to infect fungi and have no known capacity to infect humans, and most totiviruses lack the means to be transmitted extracellularly. IMNV is an exception (Fig. 1) and therefore may be an interesting candidate for genetic engineering to expand its host range [80]. Similar to the surface fibers in other viruses, the IMNV protrusions are almost certainly involved in cell entry, including receptor binding and/or membrane penetration, i.e. confer host specificity. Exploring if genetic modification of IMNV protrusions generates a chimeric virus that is able to selectively infect fungi via an extracellular mode of transmission may be an interesting field of research.

\section{Mycoviruses as gene vectors}

Another possible scenario, apart from generating a chimeric mycovirus that is efficiently transmitted extracellularly, may be its use as a gene insertion vector. As such, the virus does not need to be detrimental to the fungus itself, as is the case for most mycoviruses in their natural life cycle, but the mycovirus should be able to function as a "Trojan horse", expressing foreign inserts "upon request" (Table 2). This has already been applied in fighting fungal diseases in plants using killer toxins (discussed above) [81]. The gene encoding a broad spectrum yeast killer toxin was inserted in Potato virus $\mathrm{X}$ and yielded particles displaying an active form of the killer peptide against the plant pathogenic fungi of interest and, additionally, also displayed activity against C. albicans [81].

Of note, recombinant mycoviruses have to meet various criteria and characteristics. Research into the field of mycoviruses can only be performed in a model system that offers a high virus yield and is safe at the same time with the lowest risk possible of emergence of viruses capable of infecting humans. Characteristics required are summarised in Table 2.
Table 2 Ideal characteristics of mycoviruses intended to be used as biocontrol agents of invasive fungal infections in humans

\begin{tabular}{lc}
\hline The mycovirus should & The mycovirus should \\
NOT
\end{tabular}

\section{Overcoming the cell wall barrier}

As explained before, the fungal cell wall poses a barrier to viral entry. Different types of strategies can be hypothesized to overcome this obstacle. One such strategy may be pretreatment with an antifungal agent to induce holes in the fungal wall thus exposing the cell membrane surface to mycovirus application. Another strategy may be the use of delivery systems. Because dsRNA viruses are approximately 2.5 times smaller than empty Amphotericin B liposomes which measure $100 \mathrm{~nm}$ (Gilead Science), liposomes are an interesting delivery system. The delivery system, or the mycovirus itself, may be expressing enzymes that have chitinase of glucanase activity. Again, this idea was strengthened by observations from studying bacteriophages. Bacteria sometimes produce thick polysaccharide capsules for protection in hostile environments which also limits infection with bacteriophages. Some bacteriophages, however, express enzymes with capsule-depolymerizing activities. Bacteriophages expressing these enzymes that are attached via an adapter protein to the virus portal vertex through which the DNA is ejected during infection are able to digest their way through $400-\mathrm{nm}$ thick capsules $[82,83]$.

\section{Conclusion}

In their natural life cycle, mycoviruses are usually nontransmissible by an extracellular route and cause persistent 
infections in their host without phenotypic alterations. However, based on results obtained with chimeric plant viruses, bacteriophages and pyocins, genetic engineering of existing mycoviruses is possible. Mycovirus therapy may thus be regarded as an interesting and promising direction for future research and may provide an alternative therapeutic biological agent against invasive fungal infections.

\section{References}

1. Pfaller MA, Diekema DJ (2007) Epidemiology of invasive candidiasis: a persistent public health problem. Clin Microbiol Rev 20:133-163

2. Slobbe L, Polinder S, Doorduijn JK et al (2008) Outcome and medical costs of patients with invasive aspergillosis and acute myelogenous leukemia-myelodysplastic syndrome treated with intensive chemotherapy: an observational study. Clin Infect Dis 47:1507-1512

3. Hollings M (2009) Viruses associated with a die-back disease of cultivated mushroom. Nature 196:962-965

4. Pearson MN, Beever RE, Boine B, Arthur K (2009) Mycoviruses of filamentous fungi and their relevance to plant pathology. Mol Plant Pathol 10:115-128

5. Fauquet CM, Mayo MA, Maniloff J, Desselberger U, Ball LA eds (2005) Virus taxonomy: eighth report of the International Committee on Taxonomy of Viruses. Elsevier Academic Press, San Diego

6. Bozarth RF (1972) Mycoviruses: a new dimension in microbiology. Environ Health Perspect 2:23-39

7. Border DJ, Buck KW, Chain EB, Kempson-Jones GF, Lhoas P, Ratti G (1972) Viruses of Penicillium and Aspergillus species. Biochem J 127:4P-6P

8. van Diepeningen AD, Debets AJ, Hoekstra RF (2006) Dynamics of dsRNA mycoviruses in black Aspergillus populations. Fungal Genet Biol 43:446-452

9. van Diepeningen AD, Debets AJ, Hoekstra RF (1998) Intra- and interspecies virus transfer in Aspergilli via protoplast fusion. Fungal Genet Biol 25:171-180

10. El-Sherbeini M, Bostian KA (1987) Viruses in fungi: infection of yeast with the K1 and K2 killer viruses. Proc Natl Acad Sci U S A 84:4293-4297

11. Papp T, Nyilasi I, Fekete C, Ferenczy L, Vagvolgyi C (2001) Presence of double-stranded RNA and virus-like particles in Rhizopus isolates. Can J Microbiol 47:443-447

12. Vagvolgyi C, Magyar K, Papp T et al (1998) Detection of doublestranded RNA molecules and virus-like particles in different Mucor species. Antonie Leeuwenhoek 73:207-210

13. Mehta RJ, Nash CH 3rd, Bozzola JJ (1982) Virus-like particles and lytic plaque formation in lawns of Candida albicans. J Bacteriol 152:502-505

14. Matte O, Chabalier C, Ratomahenina R, Bossy JP, Galzy P (1990) Isolation and characterization of a RNA-virus like particle from Candida curvata. Biol Cell 68:159-162

15. Hammond TM, Andrewski MD, Roossinck MJ, Keller NP (2008) Aspergillus mycoviruses are targets and suppressors of RNA silencing. Eukaryot Cell 7:350-357

16. Nesterova GF, Kiarner I, Soom I (1973) Virus-like particles in Candida tropicalis. Mikrobiologiia 42:162-165

17. El-Sherbeini M, Bostian KA, Levitre J, Mitchell DJ (1987) Geneprotein assignments within the yeast Yarrowia lipolytica dsRNA viral genome. Curr Genet 11:483-490

18. Aoki N, Moriyama H, Kodama M, Arie T, Teraoka T, Fukuhara T(2009) A novel mycovirus associated with four double-stranded RNAs affects host fungal growth in Alternaria alternata. Virus Res 140:179-187
19. Coenen A, Kevei F, Hoekstra RF (1997) Factors affecting the spread of double-stranded RNA viruses in Aspergillus nidulans. Genet Res 69:1-10

20. Hillman BI, Suzuki N (2004) Viruses of the chestnut blight fungus, Cryphonectria parasitica. Adv Virus Res 63:423-472

21. van Diepeningen AD, Debets AJ, Hoekstra RF (1997) Heterokaryon incompatibility blocks virus transfer among natural isolates of black Aspergilli. Curr Genet 32:209-217

22. Liu YC, Linder-Basso D, Hillman BI, Kaneko S, Milgroom MG (2003) Evidence for interspecies transmission of viruses in natural populations of filamentous fungi in the genus Cryphonectria. Mol Ecol 12:1619-1628

23. Fedorova ND, Badger JH, Robson GD, Wortman JR, Nierman WC (2005) Comparative analysis of programmed cell death pathways in filamentous fungi. BMC Genomics 6:177

24. Davies JR, Osmani AH, De Souza CP, Bachewich C, Osmani SA (2004) Potential link between the NIMA mitotic kinase and nuclear membrane fission during mitotic exit in Aspergillus nidulans. Eukaryot Cell 3:1433-1444

25. Fedorova ND, Khaldi N, Joardar VS et al (2008) Genomic islands in the pathogenic filamentous fungus Aspergillus fumigatus. PLoS Genet 4:e1000046

26. van Diepeningen $\mathrm{AD}$, Pal $\mathrm{K}$, van der Lee TA, Hoekstra RF, Debets AJ (2009) The het-c heterokaryon incompatibility gene in Aspergillus niger. Mycol Res 113:222-229

27. Yphantis DA, Dainko JL, Schlenk F (1967) Effect of some proteins on the yeast cell membrane. J Bacteriol 94:1509-1515

28. Sasaki A, Kanematsu S, Onoue M, Oyama Y, Yoshida K (2006) Infection of Rosellinia necatrix with purified viral particles of a member of Partitiviridae (RnPV1-W8). Arch Virol 151:697-707

29. Hillman BI, Supyani S, Kondo H, Suzuki N (2004) A reovirus of the fungus Cryphonectria parasitica that is infectious as particles and related to the coltivirus genus of animal pathogens. J Virol 78:892-898

30. Chen B, Craven MG, Choi GH, Nuss DL (1994) cDNA-derived hypovirus RNA in transformed chestnut blight fungus is spliced and trimmed of vector nucleotides. Virology 202:441-448

31. Buck KW (1986) Fungal virology - an overview. In: Buck KW (ed) Fungal virology. CRC Press, Florida, pp 1-84

32. Polashock JJ, Bedker PJ, Hillman BI (1997) Movement of a small mitochondrial double-stranded RNA element of Cryphonectria parasitica: ascospore inheritance and implications for mitochondrial recombination. Mol Gen Genet 256:566-571

33. Park SM, Choi ES, Kim MJ, Cha BJ, Yang MS, Kim DH (2004) Characterization of HOG1 homologue, cpMK1, from Cryphonectria parasitica and evidence for hypovirus-mediated perturbation of its phosphorylation in response to hypertonic stress. Mol Microbiol 51:1267-1277

34. Deng F, Allen TD, Hillman BI, Nuss DL (2007) Comparative analysis of alterations in host phenotype and transcript accumulation following hypovirus and mycoreovirus infections of the chestnut blight fungus Cryphonectria parasitica. Eukaryot Cell 6:1286-1298

35. Jiang D, Ghabrial SA (2004) Molecular characterization of Penicillium chrysogenum virus: reconsideration of the taxonomy of the genus Chrysovirus. J Gen Virol 85:2111-2121

36. Schmitt MJ, Poravou O, Trenz K, Rehfeldt K (1997) Unique double-stranded RNAs responsible for the anti-Candida activity of the yeast Hanseniaspora uvarum. J Virol 71:8852-8855

37. Park CM, Banerjee N, Koltin Y, Bruenn JA (1996) The Ustilago maydis virally encoded KP1 killer toxin. Mol Microbiol 20:957963

38. Gage MJ, Bruenn J, Fischer M, Sanders D, Smith TJ (2001) KP4 fungal toxin inhibits growth in Ustilago maydis by blocking calcium uptake. Mol Microbiol 41:775-785 
39. Li N, Erman M, Pangborn W et al (1999) Structure of Ustilago maydis killer toxin KP6 alpha-subunit. A multimeric assembly with a central pore. J Biol Chem 274:20425-20431

40. Schmitt MJ, Breinig F (2002) The viral killer system in yeast: from molecular biology to application. FEMS Microbiol Rev $26: 257-276$

41. Hodgson VJ, Button D, Walker GM (1995) Anti-Candida activity of a novel killer toxin from the yeast Williopsis mrakii. Microbiology 141:2003-2012

42. Weiler F, Schmitt MJ (2003) Zygocin, a secreted antifungal toxin of the yeast Zygosaccharomyces bailii, and its effect on sensitive fungal cells. FEMS Yeast Res 3:69-76

43. Cabib E, Drgon T, Drgonova J, Ford RA, Kollar R (1997) The yeast cell wall, a dynamic structure engaged in growth and morphogenesis. Biochem Soc Trans 25:200-204

44. Kurtz MB (1998) New antifungal drug targets: a vision for the future. ASM News 64:31-39

45. Hector RF (1993) Compounds active against cell walls of medically important fungi. Clin Microbiol Rev 6:1-21

46. Schmitt M, Radler F (1987) Mannoprotein of the yeast cell wall as primary receptor for the killer toxin of Saccharomyces cerevisiae strain 28. J Gen Microbiol 133:3347-3354

47. Hutchins K, Bussey H (1983) Cell wall receptor for yeast killer toxin: involvement of (1 leads to 6)-beta-D-glucan. J Bacteriol 154:161-169

48. Jablonowski D, Fichtner L, Martin VJ et al (2001) Saccharomyces cerevisiae cell wall chitin, the Kluyveromyces lactis zymocin receptor. Yeast 18:1285-1299

49. Marquina D, Santos A, Peinado JM (2002) Biology of killer yeasts. Int Microbiol 5:65-71

50. Yamamoto T, Hiratani T, Hirata H, Imai M, Yamaguchi H (1986) Killer toxin from Hansenula mrakii selectively inhibits cell wall synthesis in a sensitive yeast. FEBS Lett 197:50-54

51. Kimura T, Kitamoto N, Kito Y et al (1997) A novel yeast gene, RHK1, is involved in the synthesis of the cell wall receptor for the HM-1 killer toxin that inhibits beta-1, 3-glucan synthesis. Mol Gen Genet 254:139-147

52. Selitrennikoff CP (2001) Antifungal proteins. Appl Environ Microbiol 67:2883-2894

53. Polonelli L, Lorenzini R, De BF, Morace G (1986) Potential therapeutic effect of yeast killer toxin. Mycopathologia 96:103-107

54. Walker GM, McLeod AH, Hodgson VJ (1995) Interactions between killer yeasts and pathogenic fungi. FEMS Microbiol Lett 127:213-222

55. Magliani W, Conti S, Travassos LR, Polonelli L (2008) From yeast killer toxins to antibiobodies and beyond. FEMS Microbiol Lett 288:1-8

56. Sulakvelidze A, Alavidze Z, Morris JG Jr (2001) Bacteriophage therapy. Antimicrob Agents Chemother 45:649-659

57. Stone R (2002) Bacteriophage therapy. Stalin's forgotten cure. Science 298:728-731

58. Bradbury J (2004) "My enemy's enemy is my friend." Using phages to fight bacteria. Lancet 363:624-625

59. Biswas B, Adhya S, Washart P et al (2002) Bacteriophage therapy rescues mice bacteremic from a clinical isolate of vancomycinresistant Enterococcus faecium. Infect Immun 70:204-210

60. O'Flaherty S, Ross RP, Coffey A (2009) Bacteriophage and their lysins for elimination of infectious bacteria. FEMS Microbiol Rev 33:801-819

61. Bruttin A, Brussow H (2005) Human volunteers receiving Escherichia coli phage T4 orally: a safety test of phage therapy. Antimicrob Agents Chemother 49:2874-2878

62. Fortuna W, Miedzybrodzki R, Weber-Dabrowska B, Gorski A (2008) Bacteriophage therapy in children: facts and prospects. Med Sci Monit 14:RA126-RA132

63. Wright A, Hawkins CH, Anggard EE, Harper DR (2009) A controlled clinical trial of a therapeutic bacteriophage preparation in chronic otitis due to antibiotic-resistant Pseudomonas aeruginosa; a preliminary report of efficacy. Clin Otolaryngol 34:349-357

64. Chibani-Chennoufi S, Bruttin A, Dillmann ML, Brussow $\mathrm{H}$ (2004) Phage-host interaction: an ecological perspective. J Bacteriol 186:3677-3686

65. Scholl D, Rogers S, Adhya S, Merril CR (2001) Bacteriophage K1-5 encodes two different tail fiber proteins, allowing it to infect and replicate on both $\mathrm{K} 1$ and $\mathrm{K} 5$ strains of Escherichia coli. J Virol 75:2509-2515

66. Michel-Briand Y, Baysse C (2002) The pyocins of Pseudomonas aeruginosa. Biochimie 84:499-510

67. Uratani Y, Hoshino T (1984) Pyocin R1 inhibits active transport in Pseudomonas aeruginosa and depolarizes membrane potential. J Bacteriol 157:632-636

68. Scholl D, Martin DW Jr (2008) Antibacterial efficacy of R-type pyocins towards Pseudomonas aeruginosa in a murine peritonitis model. Antimicrob Agents Chemother 52:1647-1652

69. Nakayama K, Takashima K, Ishihara H et al (2000) The R-type pyocin of Pseudomonas aeruginosa is related to $\mathrm{P} 2$ phage, and the F-type is related to lambda phage. Mol Microbiol 38:213-231

70. Williams SR, Gebhart D, Martin DW Jr, Scholl D (2008) Retargeting R-type pyocins to generate novel bactericidal protein complexes. Appl Environ Microbiol 74:3868-3876

71. Scholl D, Cooley M, Williams SR et al (2009) An engineered Rtype pyocin is a highly specific and sensitive bactericidal agent for the food-borne pathogen Escherichia coli O157:H7. Antimicrob Agents Chemother 53:3074-3080

72. Johnson J, Lin T, Lomonossoff G (1997) Presentation of heterologous peptides on plant viruses: genetics, structure, and function. Annu Rev Phytopathol 35:67-86

73. Yusibov V, Modelska A, Steplewski K et al (1997) Antigens produced in plants by infection with chimeric plant viruses immunize against rabies virus and HIV-1. Proc Natl Acad Sci USA 94:5784-5788

74. de Felipe P, Hughes LE, Ryan MD, Brown JD (2003) Cotranslational, intraribosomal cleavage of polypeptides by the Footand-mouth disease virus 2A peptide. J Biol Chem 278:11441-11448

75. Borovsky D, Rabindran S, Dawson WO et al (2006) Expression of Aedes trypsin-modulating oostatic factor on the virion of TMV: a potential larvicide. Proc Natl Acad Sci USA 103:18963-18968

76. Cruz SS, Chapman S, Roberts AG, Roberts IM, Prior DA, Oparka KJ (1996) Assembly and movement of a plant virus carrying a green fluorescent protein overcoat. Proc Natl Acad Sci USA 93:6286-6290

77. Lico C, Chen Q, Santi L (2008) Viral vectors for production of recombinant proteins in plants. J Cell Physiol 216:366-377

78. Marchenko AN, Kozlov DG, Svirshchevskaya EV, Viskova NY, Benevolensky SV (2003) The p1 protein of the yeast transposon Tyl can be used for the construction of bi-functional virus-like particles. J Mol Microbiol Biotechnol 5:97-104

79. Poulos BT, Tang KF, Pantoja CR, Bonami JR, Lightner DV (2006) Purification and characterization of infectious myonecrosis virus of penaeid shrimp. J Gen Virol 87:987-996

80. Tang J, Ochoa WF, Sinkovits RS et al (2008) Infectious myonecrosis virus has a totivirus-like, 120-subunit capsid, but with fiber complexes at the fivefold axes. Proc Natl Acad Sci USA 105:17526-17531

81. Donini M, Lico C, Baschieri S et al (2005) Production of an engineered killer peptide in Nicotiana benthamiana by using a Potato virus X expression system. Appl Environ Microbiol 71:6360-6367

82. Scholl D, Adhya S, Merril C (2005) Escherichia coli K1's capsule is a barrier to bacteriophage T7. Appl Environ Microbiol 71:4872-4874

83. Leiman PG, Battisti AJ, Bowman VD et al (2007) The structures of bacteriophages K1E and K1-5 explain processive degradation of polysaccharide capsules and evolution of new host specificities. J Mol Biol 371:836-849 